\title{
Desflurane reduces the effective therapeutic infu- sion rate (ETI) of cisatracurium more than isoflu- rane, sevoflurane, or propofol
}

\author{
[Le desflurane, comparé à l'isoflurane, au sépoflurane ou au propofol, réduit \\ davantage la vitesse de perfusion thérapeutique utile (PTU) du cisatracurium]
}

Thomas M. Hemmerling MD DEAA, Juergen Schuettler MD, Helmut Schwilden MD PhD

Purpose: The present study investigated the interaction between the cumulative dose requirements of cisatracurium and anesthesia with isoflurane, sevoflurane, desflurane or propofol using closedloop feedback control.

Methods: Fifty-six patients ( $18-85$ yr, vitrectomies of more than one hour) were studied. In the volatile anesthetics groups, anesthesia was maintained by 1.3 MAC of isoflurane, sevoflurane or desflurane; in the propofol group, anesthesia was maintained by a continuous infusion of 6-8 $\mathrm{mg} \cdot \mathrm{kg}^{-1} \cdot \mathrm{hr}^{-1}$ propofol. After bolus application of $0.1 \mathrm{mg} \cdot \mathrm{kg}^{-1}$ cisatracurium, a TI\%-level of $10 \%$ of control level (train-of-four stimulation every $20 \mathrm{sec}$ ) was maintained using closed-loop feedback controlled infusion of cisatracurium. The effective therapeutic infusion rate (ETI) was estimated from the asymptotic steady-state infusion rate $I_{\text {ss. }}$ The $I_{s s}$ was derived from fitting an asymptotic line to the measured cumulative dose requirement curve. The ETI of the different groups was compared using Kruskal-Wallis- test, followed by rank sum test, corrected for the number of comparisons, $P<0.05$ was regarded as showing signifcant difference.

Results: $\mathrm{ETI}$ in the isoflurane group was $35.6 \pm 8.6 \mu \mathrm{g} \cdot \mathrm{m}^{-2} \cdot \mathrm{min}^{-1}$, in the sevoflurane group $36.4- \pm 11.9 \mu \mathrm{g} \mathrm{m}^{-2} \cdot \mathrm{min}^{-1}$, in the desflurane group $23.8 \pm 6.3 \mu \mathrm{g} \cdot \mathrm{m}^{-2} \cdot \mathrm{min}^{-1}$. The ETI of the volatile anesthetic groups were all significantly lower than the ETI in the propofol group at $61.7 \pm 25.3 \mu \mathrm{g} \cdot \mathrm{m}^{-2} \cdot \mathrm{min}^{-1}(P<0.002)$. The ETI in the desflurane group was significantly lower than in all other groups $(P<0.02)$.

Conclusion: In comparison to propofol, isoflurane, sevoflurane and desflurane reduce the cumulative dose requirements of cisatracurium to maintain a $90 \%$ neuromuscular blockade by $42 \%$, $41 \%$ and $60 \%$, respectively.
Objectif : Rechercher l'interaction entre la dose cumulative nécessaire de cisatracurium et l'anesthésie avec de l'isoflurane, du sévoflurane, du desflurane ou du propofol, en utilisant un système de rétroaction en boucle fermée.

Méthode : L'étude a porté sur 56 patients ( 8 -85 ans, vitrectomie de plus d'une heure). Chez les patients qui ont reçu un anesthésique volatil, l'anesthésie a été entretenue avec I,3 CAM d'isoflurane, de sévoflurane ou de desflurane; chez ceux qui ont eu du propofol, on a administré une perfusion continue de 6-8 $\mathrm{mg} \cdot \mathrm{kg}^{-1} \cdot \mathrm{h}^{-1}$ de propofol. Après l'administration d'un bolus de 0,1 $\mathrm{mg} \cdot \mathrm{kg}^{-1}$ de cisatracurium, une première réponse Tlà $10 \%$ (d'une stimulation en train-de-quatre répétée toutes les 20 s) a été maintenue au moyen d'une perfusion de cisatracurium contrôlée par un système de rétroaction en boucle fermée. La vitesse de perfusion thérapeutique utile (PTU) a été évaluée à partir de la vitesse de perfusion asymptotique àl'équilibre $P_{\mathrm{e}}$. La $P_{\mathrm{e}}$ a été dérivée de l'ajustement d'une ligne asymptotique à la courbe de la dose cumulative nécessaire. La PTU des différents groupes a été comparée à l'aide du test de Kruskal-Wallis, suivi du test de la somme des rangs, ajusté en fonction du nombre de comparaisons, $P<0,05$ a été considéré comme une différence significative.

Résultats : La PTU associée à l'isoflurane a été de 35,6 \pm 8,6 $\mathrm{mg} \cdot \mathrm{m}^{-2} \cdot \mathrm{min}^{-1}$; au sévoflurane, $36,4 \pm 11,9 \mathrm{mg} \mathrm{m} \mathrm{m}^{-2} \cdot \mathrm{min}^{-1}$ et au desflurane, 23,8 $\pm 6,3 \mathrm{mg} \cdot \mathrm{m}^{-2} \cdot \mathrm{min}^{-1}$. La PTU associée aux anesthésiques volatils a été significativement plus basse que celle qui est associée au propofol, 61,7 $\pm 25,3 \mathrm{mg} \cdot \mathrm{m}^{-2} \cdot \mathrm{min}^{-1}(P<0,002)$. La PTU associée au desflurane a été significativement plus basse que celles qui concernent tous les autres anesthésiques $(P<0,02)$. Conclusion : Comparés au propofol, l'isoflurane, le sévoflurane et le desflurane réduisent de $42 \%, 41 \%$ et $60 \%$, respectivement,

From the Department of Anesthesiology, University of Erlangen-Nuremberg, Germany.

Present correspondence address: Dr. Thomas M Hemmerling, Department of Anesthesiology, University of Montreal, CHUM - Hôtel-

Dieu, 3840, rue Saint-Urbain, Montreal, Quebec H2W 1T8, Canada. Phone: 514-843-2611, ext. 4570; Fax: 514-843-2690;

E-mail: thomashemmerling@hotmail.com

Accepted for publication February 6, 2001.

Revision accepted March 26, 2001. 
la dose cumulative nécessaire de cisatracurium pour maintenir un blocage neuromusculaire à $90 \%$.

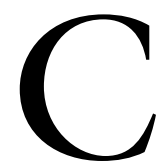

ISATRACURIUM is the 1 -R-cis-l'R-cis isomer of atracurium; in comparison to atracurium, it has a slower onset time $e^{1}$ and less propensity to liberate histamine., ${ }^{2,3}$ The reduction of the cumulative dose requirements of atracurium by volatile anesthetics has been shown in several studies. ${ }^{4}, 5$ The cumulative dose requirements of cisatracurium have not yet been determined nor has the effect of desflurane on any non-depolarizing neuromuscular blocking drug.

A recent study ${ }^{6}$ has shown that volatile anesthetics lower $\mathrm{ED}_{50}$ and $\mathrm{ED}_{95}$ of cisatracurium significantly in comparison to propofol. However, data about the influence of volatile anesthetics on the clinical duration of the neuromuscular blockade after cisatracurium were inconclusive. During surgery requesting a high and steady level of neuromuscular blockade (e.g., eye surgery) the non-depolarizing muscle relaxant can easily be applied via continuous infusion and the effect repetitively controlled.

We used a closed-loop feedback control model-driven system to administer cisatracurium to maintain a neuromuscular blockade of $90 \%$ in patients undergoing vitrectomy; the effect of desflurane, isoflurane, sevoflurane, or propofol on the infusion requirements of cisatracurium was measured by calculating the effective therapeutic infusion rate (ETI) to maintain a level of neuromuscular blockade at $90 \%$ of control twitch height of the first twitch amplitude (Tl).

Materials and methods

After obtaining approval by the local Ethics Committee and written informed consent, 56 patients (ASA I-III) undergoing vitrectomy of an anticipated duration of more than one hour were studied. Patients with neuromuscular disorders or patients on medication known to interact with neuromuscular blockade were excluded from the study. Ten milligrams of chlorazepatedipotassium was given orally at 22:00 hr on the evening before the operation and one hour prior to the start of anesthesia. Anesthesia was induced with $0.3 \mathrm{mg} \cdot \mathrm{kg}^{-1}$ etomidate and $10 \mu \mathrm{g} \cdot \mathrm{kg}^{-1}$ alfentanil. The Relaxograph ${ }^{\circledR}$ (Datex Instrumentarium, Helsinki, Finland) was used to measure the train-of-four (TOF) response from the adductor pollicis muscle over the thenar area via surface skin electrodes. After induction of anesthesia the Relaxograph ${ }^{\circledR}$ was automatically calibrated by setting optimum signal levels at supramaximal stimulation (TOF stimulation for five minutes in all patients before application of cisatracurium). The TOF sequence was assessed every $20 \mathrm{sec}$; the degree of neuromuscular blockade was defined as the ratio of the first twitch in the TOF-ratio compared to the corresponding control value ( $\mathrm{Tl} \%)$.

Neuromuscular blockade then was induced by injecting $0.1 \mathrm{mg} \cdot \mathrm{kg}^{-1}$ cisatracurium $\left(2 \times \mathrm{ED}_{95}\right)$ intravenously. After complete neuromuscular blockade (Tl\% $<5 \%)$, endotracheal intubation was performed. Body temperature was monitored at the hand and kept above 35.6C using a heating blanket (Bair Hugger, MN, USA).

Patients were randomly assigned to one of the four groups: in the isoflurane, sevoflurane, desflurane groups (groups I, S, D), general anesthesia was maintained by end-tidal 1.3 MAC of each volatile anesthetic in oxygen/air (30\% oxygen). In the propofol group (group P), anesthesia was maintained by a continuous infusion of $6-8 \mathrm{mg} \cdot \mathrm{kg}^{-1} \cdot \mathrm{hr}^{-1}$ of propofol; as breathing gas an oxygen/air mixture (30\% oxygen) was used. Alfentanil was given at the discretion of the anesthesiologist (not more than $1 \mathrm{mg}$ alfentanil. $\mathrm{hr}^{-1}$ of surgery). Patients were kept in normoventilation with an end-tidal carbon dioxide of $30-40 \mathrm{mmHg}$.

After the bolus administration, cisatracurium was infused intravenously according to a model-driven, closed-loop feedback system. The Infusomat $\mathrm{CP} \circledast$ (Fresenius, Bad Homburg, Germany) and the Relaxograph ${ }^{\circledR}$ were connected to a Toshiba ${ }^{\circledR} \mathrm{T}$ 1850C laptop via a serial RS $232 \mathrm{C}$ interface. The set point of neuromuscular blockade was defined as $\mathrm{T} 1 \%=10 \%$; the controller performance was calculated as the mean offset of the measured $\mathrm{Tl} \%$ from the set point during feedback control.

\section{Statistical analysis}

Difference of means and standard deviation of $\mathrm{I}_{\mathrm{ss}}(4,5)$ was used to determine group size for a power of more than 0.9 (beta error $=10 \%)$. The ETI $\left(\mu \mathrm{g} \mathrm{x} \mathrm{m}^{-2}\right.$ body surface area $\times \mathrm{min}^{-1}$ ) maintaining $90 \%$ of neuromuscular blockade was estimated from the asymptotic steady-state infusion rate $\mathrm{I}_{s s} \mathrm{I}_{s s}$ was calculated by fitting an asymptotic line to the measured cumulative dose requirement curve using least square fitting (see appendix).

Parameters were compared using Kruskal-Wallistest, followed by rank sum test, corrected for the number of comparisons, $P<0.05$ was regarded as showing statistical significance. Correlation between anthropometric data and ETI for each group was tested by Spearman's test $(P<0.05)$.

\section{Results}

The anthropometric data, the duration of feedback control and the controller performance for each group 
TABLE Patient data, feedback, control period and controller performance (mean offset from set-point: 90\% blockade of control value)

\begin{tabular}{llllllll}
\hline Groups & ASA & $\begin{array}{l}\text { Sex } \\
(\mathrm{m} / f)\end{array}$ & $\begin{array}{l}\text { Age } \\
(\mathrm{y})\end{array}$ & $\begin{array}{l}\text { Weight } \\
(\mathrm{kg})\end{array}$ & $\begin{array}{l}\text { Body surface } \\
\text { area }\left(\mathrm{m}^{2}\right)\end{array}$ & $\begin{array}{l}\text { Feedback } \\
\text { control }\end{array}$ & $\begin{array}{l}\text { Mean offset } \\
\text { from set point }\end{array}$ \\
\hline $\mathrm{I}$ & $\mathrm{I}, \mathrm{II}, \mathrm{III}$ & $9 / 5$ & $56(19)$ & $83(15)$ & $1.93(0.19)$ & $118(41)$ & $3.19(1.78)$ \\
$\mathrm{S}$ & $2,5,7$ & $6 / 8$ & $61(17)$ & $72(13)$ & $1.81(0.21)$ & $83(22)$ & $2.06(1.56)$ \\
$\mathrm{D}$ & $2,5,7$ & $8 / 6$ & $61 / 20$ & $74(9)$ & $1.86(0.12)$ & $97(35)$ & $2.00(1.51)$ \\
$\mathrm{P}$ & $4,5,5$ & $51(18)$ & $81(14)$ & $1.93(0.21)$ & $88(20)$ & $2.49(1.65)$ \\
\hline
\end{tabular}

Values are mean \pm SD.

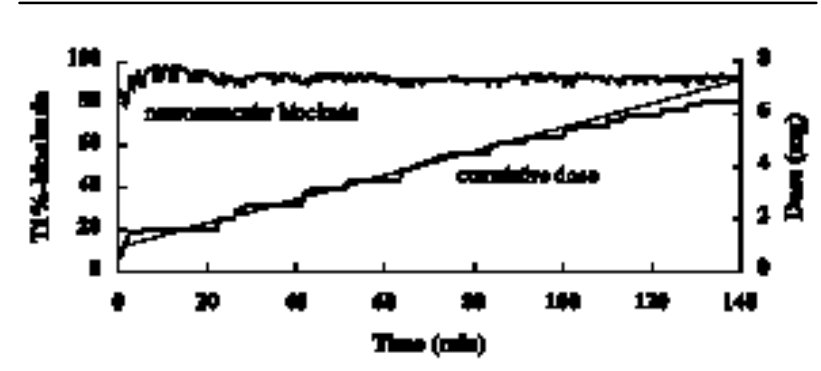

FIGURE 1 Data for one representative patient; the figure shows the time course of the neuromuscular blockade and the cumulative dose requirements; $\mathrm{I}_{\text {ss }}$ is calculated by non-linear curve fitting (least square fitting, dotted straight line). ETI: $32 \mu \mathrm{g} \cdot \mathrm{m}^{-2} \cdot \mathrm{min}^{-1}$, isoflurane group.

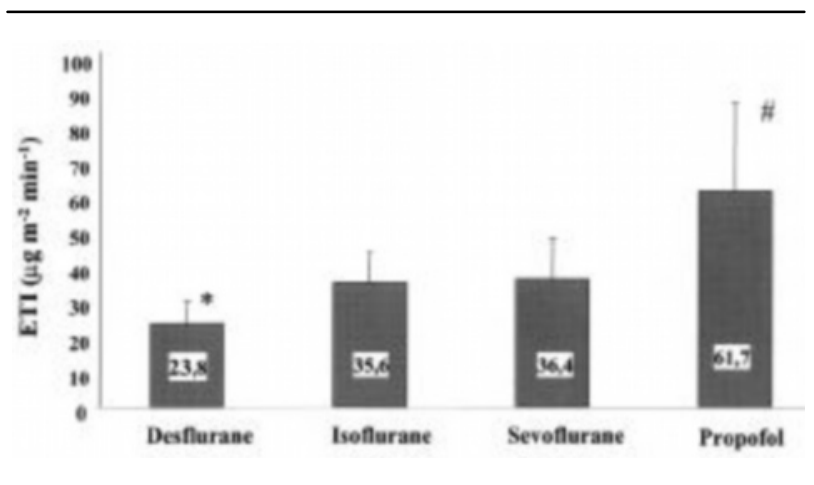

FIGURE 2 Shows the ETI for all groups. \#P<0.002: ETI (propofol) vs ETI (volatile anesthetics); ${ }^{*} P<0.02$ : ETI (desflurane) vs ETI (propofol, sevoflurane, isoflurane).

are shown in the Table. There were no significant differences in sex distribution, age, and weight or ASA classification between the groups. The controller performance was not different between the groups. All patients completed the study according to the protocol, there were no technical problems with the closed loop delivery system. The mean duration between cisatracurium bolus application and start of the closed loop control was $22 \pm 5 \mathrm{~min}$. The mean duration of cisatracurium-infusion was longest in the isoflurane group (118 min) without being statistically significantly different from the other groups. The neuromuscular blockade after bolus administration of $0.1 \mathrm{mg} \cdot \mathrm{kg}^{-1}$ cisatracurium achieved levels of more than $95 \%$ blockade of $\mathrm{Tl} \%$ in all patients at a mean of $210 \pm 55 \mathrm{sec}$, thus providing good conditions for intubation.

Figure 1 demonstrates an example of the time course of neuromuscular blockade and the cumulative dose requirements for one representative patient. Figure 2 shows the ETI to maintain the desired level of neuromuscular blockade for each group. The ETI was lowest in group D at $23.8 \pm 6.3 \mu \mathrm{g} \mathrm{m} \mathrm{m}^{-2} \cdot \mathrm{min}^{-1}(P$ $<0.02)$, and highest at $61.7 \pm 25.3 \mu \mathrm{g} \cdot \mathrm{m}^{-2} \cdot \mathrm{min}^{-1}$ in group $\mathrm{P}(P<0.002)$. The ETI in groups I and $S$ did not differ statistically. There was no correlation between the age and weight of patients and the ETI.

Discussion

Isoflurane, sevoflurane and desflurane at 1.3 MAC reduce the cumulative dose requirements of cisatracurium by $42 \%, 41 \%$ and $60 \%$ in comparison to propofol at 6-8 $\mathrm{mg} \cdot \mathrm{kg}^{-1} \cdot \mathrm{hr}^{-1}$. Desflurane significantly reduced the cumulative dose requirements of cisatracurium in comparison to sevoflurane and isoflurane.

Cisatracurium has widely replaced atracurium because of the absence of histamine liberation., ${ }^{2,3}$ Using $0.1 \mathrm{mg} \cdot \mathrm{kg}^{-1}$ cisatracurium for intubation followed by a closed-loop feedback controlled infusion, no sign of histamine liberation such as skin rash or changes in hemodynamics were noticed. The onset time of the bolus application of $0.1 \mathrm{mg} \cdot \mathrm{kg}^{-1}$ cisatracurium at the adductor pollicis muscle was between three to five minutes, comparable to results in other studies. ${ }^{7-9}$

The controller performance was regarded as sufficient at an average difference from $2.0 \%$ (group D) to $3.2 \%$ (group I) between the set point of T1\%=10\% and the measured degree of neuromuscular blockade. The controller performance for cisatracurium was different 
from those found for other non-depolarizing muscle relaxants such as vecuronium, ${ }^{10,11}$ atracurium ${ }^{12,13}$ or rocuronium. ${ }^{14}$ In the latter study, Olkkola $e t$ al. investigated the interaction of rocuronium with several iv anesthetics or isoflurane; the best controller performance values were achieved at $0.2 \%$ to $0.8 \%$ average offset from set point. The controller performance found in our study could have been anticipated because cisatracurium shows a more marked hysteresis and slower onset time than the other three non-depolarizing muscle relaxants. Wulf et al. ${ }^{6}$ recently showed a significant decrease of $\mathrm{ED}_{50}$ and $\mathrm{ED}_{95}$ of cisatracurium during anesthesia with 1.5 MAC (in a mixture of $70 \%$ nitrous oxide $/ 30 \%$ oxygen) of desflurane, sevoflurane or isoflurane in comparison to propofol. It is interesting to note that the time to reach $25 \%$ of control level of

TOF stimulation was not statistically different between the groups, but recovery index and time to reach a TOF ratio of 0.7 were significantly prolonged during anesthesia with desflurane and sevoflurane in comparison to propofol, but not so for isoflurane. There are, however, several limitations to that study. The cumulative dose technique might underestimate the potency of the neuromuscular blocking drugs. Diffusion of the inhaled anesthetic requires more than $30 \mathrm{~min}$ to reach equilibrium and this time span is different for the volatile anesthetic tested. Hendricks et $a l .{ }^{15}$ showed that uptake for desflurane and isoflurane might even take up to an hour. These findings limit at least the interpretation of the degree of $\mathrm{ED}_{50}$ or $\mathrm{ED}_{95}$ reductions. Wulf $e t$ al. admit themselves that the application of the total dose in increments could have underestimated the effect of the duration of action of cisatracurium during continuous infusion of propofol. Finally, in contrast to the current study, which used the algorithm presented by Mapleson ${ }^{16}$ to calculate the agerelated adaptation of MAC value for each patient, the Vol \% equalling MAC was not adjusted to age. However, 1 MAC of desflurane in $100 \%$ oxygen for a 40 -yr-old patient would be $6.6 \mathrm{Vol} \%$ in comparison to $5.1 \mathrm{Vol} \%$ for an 80 -yr-old patient, a difference of $25 \%$.

In contrast to the present study, most studies have compared cumulative dose requirements of volatile anesthetics in breathing gas mixtures including nitrous oxide. A recent study, ${ }^{17}$ however, shows by calculating isoboles for desflurane and cumulative doses of nitrous oxide, that the decrease of the required desflurane concentrations by the administration of nitrous oxide might be less than expected from their MAC values. This could mean that for different volatile anesthetics, the additive effect of nitrous oxide might be different, limiting the comparability of the studies. In the current study, all volatile anesthetics were compared in a breathing gas mixture consisting of air/oxygen (30\% oxygen).

It could be assumed that the significant $20 \%$ reduction of the cumulative cisatracurium dose requirement of desflurane in comparison to isoflurane and sevoflurane is due to a different depth of anesthesia achieved by 1.3 MAC of desflurane. Kansanaho et al. ${ }^{13}$ studied the influence of several doses of enflurane on the cumulative dose requirements of atracurium to maintain a constant $90 \%$ neuromuscular block; this study showed that enflurane decreased the atracurium requirements in a dose-dependant manner: 0.5 MAC of enflurane reduced the atracurium requirements by $20 \%, 1$ MAC by $25 \%$ and 1.3 MAC reduced the $\mathrm{I}_{\text {ss }}$ of atracurium by $28 \%$. The assumption that $1 \mathrm{MAC}$ of desflurane might create a different depth of anesthesia than I MAC of sevoflurane or isoflurane cannot, how ever, be supported by a recent study by Rehberg et al. ${ }^{8}$ In a study of pharmacodynamic modelling of the EEG slowing effect of isoflurane, sevoflurane and desflurane, these authors have shown that MAC and MAC multiples are valid representations of the concentration response curve for the anesthetic suppression of the $95^{\text {th }}$ percentile of the power spectrum with no significant difference of the $\mathrm{EC}_{50}$ values.

The effect of desflurane on cumulative dose requirements using closed loop feedback systems had not been studied previously. Several studies, however, have determined the effect of desflurane on the recovery of neuromuscular blockade of vecuronium, ${ }^{19}$ mivacurium $^{20}$ and rapacuronium. ${ }^{2}{ }^{1}$ Desflurane prolonged the recovery of neuromuscular blockade of those non-depolarizing blocking drugs in a degree similar to sevoflurane or isoflurane.

One reason for the significantly higher ETI reduction by desflurane in comparison to sevoflurane or isoflurane might be the need for a much higher partial pressure to achieve the same MAC multiples because of its weaker anesthetic potency.

In our study, isoflurane, sevoflurane and desflurane at 1.3 MAC reduced the cumulative dose requirements of cisatracurium by $42 \%, 41 \%$ and $60 \%$ in comparison to propofol at $6-8 \mathrm{mg} \cdot \mathrm{kg}^{-1} \cdot \mathrm{hr}^{-1}$. Our findings did not differ from other investigators who - in contrast to animal studies $-22,23$ could not show any interaction between iv anesthetic agents such as midazolam, etomidate, thiopental or fentanyl and muscle relaxants. ${ }^{14}$ Propofol seems to show an interaction similar to these other agents.

The clinical implication of this study is that the dose of cisatracurium required to maintain a given degree of neuromuscular blockade is influenced by volatile anesthetics as much as for other muscle relax- 
ants such as vecuronium, rocuronium or atracurium and needs to be adjusted accordingly. It is noteworthy that desflurane reduced the ETI of cisatracurium in comparison to sevoflurane or isoflurane by a further $20 \%$; this might have economic implications in surgeries such as neurosurgical procedures where a high degree of neuromuscular blockade must be maintained for a long period of time but short awakening times are desirable. Large interindividual differences, however, and the absence of any correlation between patient characteristics, such as age, weight or even body surface area, and the ETI to maintain the desired level of neuromuscular blockade make monitoring of the neuromuscular function mandatory. When monitoring neuromuscular blockade at the adductor pollicis muscle, one should remember the shorter onset, faster recovery and less intense block at the orbicularis oculi muscle ${ }^{2}$ for appropriate site-related relaxation.

\section{References}

1 Lepage JY, Malinovsky JM, Malinge M, Cozian A, Pinand M. Comparison of equipotent doses of 51W89 and atracurium. Anesthesiology 1994; 81: A1090 (abstract).

2 Lien CA, Belmont MR, Abalos A, et al. The cardiovascular effects and histamine-releasing properties of 51W89 in patients receiving nitrous oxide/opioid/barbiturate anesthesia. Anesthesiology 1995; 82: 1131-8.

3 Doenicke A, Soukup J, Hoernecke R, Moss J. The lack of histamine release with cisatracurium: a double-blind comparison with vecuronium. Anesth Analg 1997; 84: 623-8.

4 Vanlinthout LEH, Booij LHD, Van Egmond J, Robertson EN. Effect of isoflurane and sevoflurane on the magnitude and time course of neuromuscular block produced by vecuronium, pancuronium and atracurium. Br J Anaesth 1996; 76: 389-95.

5 O'Hara DA, Derbyshire GJ, Overdyk FJ, Bogen DK, Marshall $B E$. Closed-loop infusion of atracurium with four different anesthetic techniques. Anesthesiology 1991; 74: 258-63.

6 Wulf H, Kabl M, Ledowski T. Augmentation of the neuromuscular blocking effects of cisatracurium during desflurane, sevoflurane, isoflurane or total i.v. anaesthesia. Br J Anaesth 1998; 80: 308-12.

7 Kim KS, Chung CW, Shin WJ. Cisatracurium neuromuscular block at the adductor pollicis and the laryngeal adductor muscles in humans. Br J Anaesth 1999; 83: 483-4.

8 Carroll MT, Mirakbur RK, Lowry DW, McCourt KC, $\operatorname{Kerr} C$. Neuromuscular blocking effects and train- offour fade with cisatracurium: comparison with other nondepolarising relaxants. Anaesthesia 1998; 53: 1169-73.
9 Mellinghoff H, Radbruch L, Diefenbach C, Buzello W. A comparison of cisatracurium and atracurium: onset of neuromuscular block after bolus injection and recovery after subsequent infusion. Anesth Analg 1996; 83: $1072-5$.

10 Olkkola KT, Schwilden H. Adaptive closed-loop feedback control of vecuronium-induced neuromuscular relaxation. Eur J Anaesth 1991; 8: 7-12.

11 Olkkola KT, Kansanaho M. Quantifying the interaction of vecuronium with enflurane using closed-loop feedback control of vecuronium infusion. Acta Anaesthesiol Scand 1995; 39: 489-93.

12 Olkkola KT, Schwilden H. Quantitation of the interaction between atracurium and succinylcholine using closed-loop feedback control of infusion of atracurium. Anesthesiology 1990; 73: 614-8.

13 Kansanaho M, Olkkola KT. Quantifying the effect of enflurane on atracurium infusion requirements. Can J Anaesth 1995; 42: 103-8.

14 Olkkola KT, Tammisto T. Quantifying the interaction of rocuronium (Org 9426) with etomidate, fentanyl, midazolam, propofol, thiopental, and isoflurane using closed-loop feedback control of rocuronium infusion. Anesth Analg 1994; 78: 691-6.

15 Hendrickx JFA, Soetens M, Van der Donck A, Meeuwis $H$, Smolders F, De Wolf AM. Uptake of desflurane and isoflurane during closed-circuit anesthesia with spontaneous and controlled mechanical ventilation. Anesth Analg 1997; 84: 413-8.

16 Mapleson $W W$. Effect of age on MAC in humans: a meta-analysis. Br J Anaesth 1996; 76: 179-85.

17 Ropcke H, Wartenberg HC, Konen-Bergmann M. The interaction of desflurane and nitrous oxide on EEG during surgical stimulation is additive. Anesthesiology 1998; 89: Al08 (abstract).

18 Rehberg B, Bouillon T, Zinserling J, Hoeft A Comparative pharmacodynamic modeling of the electroencephalography-slowing effect of isoflurane, sevoflurane, and desflurane. Anesthesiology 1999; 91: 397-405.

19 Ghouri AF, White PF. Comparative effects of desflurane and isoflurane on vecuronium-induced neuromuscular blockade. J Clin Anesth 1992; 4: 34-8.

20 Gan TJ, Quill TJ, Pressley C, Parrillo S, Glass PSA. A comparison of mivacurium dosage requirements during isoflurane and desflurane anesthesia. J Clin Anesth 1996; 8: 301-6.

21 Zhou TJ, Coloma M, White PF, et al. Spontaneous recovery profile of rapacuronium during desflurane, sevoflurane, or propofol anesthesia for outpatient laparoscopy. Anesth Analg 2000; 91: 596-600.

22 Khuenl-Brady KS, Agoston S, Miller RD. Interaction of ORG 9426 and some of the clinically used intravenous 
anaesthetic agents in the cat. Acta Anaesthiol Scand 1992; 36: 260-3.

23 Krieg N, Rutten JMJ, Crul JF, Booij LHDJ.

Preliminary review of the interactions of ORG NC 45

with anaesthetics and antibiotics in animals. $\mathrm{Br} \mathrm{J}$

Anaesth 1980; 52: 33S-6S.

24 de Rossi L, Fritz H, Krober L, Klein U. Cisatricurium in the orbicularis oculi muscle. Comparisn of the neuromuscular action of cisatracurium and atracurium in the orbicularis oculi muscle and the adductor pollicis muscle. (German). Anaesthesist. 1999; 48: 602-6.

Appendix

Estimating the Effective Therapeutic Infusion rate (ETI)

Given a drug disposition function of the form

$$
\mathrm{G}(\mathrm{t})=\mathrm{Ae}^{-\mathrm{t}}+\mathrm{Be}^{-\beta \mathrm{t}}+\mathrm{Ce}^{-\gamma t} \ldots
$$

the cumulative drug requirement $\mathrm{D}(\mathrm{t})$ to maintain a given plasma concentration $c_{0}$ is given by

$$
D(t)=V_{c} c_{0}\left(1+k_{e l} t+\frac{k_{12}}{k_{21}}\left(1 \quad e^{k_{21} t}\right)+\frac{k_{13}}{k_{31}}\left(1 e^{k_{31} t}\right)+\ldots\right.
$$

whereby $\mathrm{V}_{c}$ denotes the central volume of distribution and $\mathrm{k}_{\mathrm{ij}}$ the transfer micro-constants associated with the hybrid constants $\mathrm{A}, \mathrm{B}, \mathrm{B}, \mathrm{C}, \gamma \ldots$

The asymptote $\mathrm{A}(\mathrm{t})$ to the cumulative drug requirement is a straight line.

$$
\mathrm{A}(\mathrm{t})=\mathrm{D}_{0}+\mathrm{I}_{\mathrm{a} s} \mathrm{t}
$$

the slope Ias of which defines an infusion rate. If $\mathrm{D}(\mathrm{t})$ is measured at constant drug effect, than Ias denotes the infusion rate which is effective to maintain that effect at steady-state $\left(\mathrm{I}_{s}\right)$. If the effect was chosen within the therapeutic window, $I_{\text {a s }}$ defines an effective therapeutic infusion (ETI).

This infusion rate can be estimated by least square fitting the above formula for $\mathrm{D}(\mathrm{t})$ to the measured cumulative drug requirement as identified by the closed loop system. 